\title{
The Design and Analysis on intensity of Anti-roll Bar on $100 \%$ Low-floor Light Rail Vehicle
}

\author{
Kuangyan Zhang ${ }^{1,}$, Zhenggang $\mathrm{Lu}^{2, \mathrm{~b}}$ \\ ${ }^{1}$ Institute of Rail Transit, Tongji University, Shanghai 201804, China; \\ ${ }^{2}$ Institute of Rail Transit, Tongji University, Shanghai 201804, China. \\ a960697667@QQ.com, b1434208@tongji.edu.cn
}

Keywords: anti-roll bar, flexibility coefficient, Dassault CATIA V5, finite element analysis.

\begin{abstract}
Anti-roll bar is mounted enhance the stiffness of rolling stock. According to the standard of flexibility coefficient, this paper introduces a method to design the Anti-roll bar of $100 \%$ low-floor light rail vehicles. After finishing the designed model, use the finite element analysis to analyze the strength of Anti-roll bar to make sure it is feasible.
\end{abstract}

\section{Introduction}

In order to meet the requirements of vehicle operation comfort, rail vehicle secondary suspension systems are generally designed to be relatively soft, but too soft secondary suspension system makes the vehicle anti-roll stiffness decreases when the vehicle is parked in the presence of ultra-high curved track, and because of the presence of ultra-suspension system is too small will lead to anti-roll stiffness of the vehicle roll angle increasing beyond the bound, even my cause the vehicle to overturn [1]. Therefore, in the rail vehicle systems, generally used to evaluate the extent of the flexibility coefficient of the vehicle overturning. Internationally we generally use the UIC 505-5: 1997 to calculate the flexible coefficient and evaluate the vehicle. If the flexible coefficient of the vehicle exceeds regulatory requirements, namely suspension anti-roll stiffness of the low side of the system, the measures taken are generally attached to the bogie anti-roll bar to make up the side of the vehicle roll stiffness. Anti-roll bar only has the resistant to the side of the vehicle rolling motion. Its role is to increase the roll stiffness of the side of the vehicle, namely an increase of Secondary bogie roll stiffness.

\section{The Calculation of flexibility coefficient}

According to UIC 505 -5: 1997 "UIC 505-1 to 505-4 general basic conditions, notes and regulations", flexible coefficient S is defined as follows: when the vehicle is still parked in the ultra-high line, assuming that the vehicle cross-sectional center on-line and the line cross section perpendicular to the centerline of the angle between the plane of the rail head is $\gamma$, and the ratio of its line of ultra-high angle $\delta$ is flexible coefficient S [2]. Flexibility coefficient S should not exceed 0.4 [3]. The parameters of a carriage when it is in AW3 conditions are shown in Table 1.

$$
\begin{aligned}
& S=\frac{\gamma}{\delta}=\left[\left(1-\frac{h_{3}}{h_{2}}\right)\left(1-\frac{G_{1} h_{1}+G_{2} h_{3}}{2 C_{1} b_{1}^{2}}\right)+\frac{2 C_{2} b_{2}^{2}+K_{\Phi r}}{2 C_{1} b_{1}^{2}}\left(1+\frac{G_{1} h_{1}}{G_{2} h_{2}}+\frac{G_{2}}{h_{2} C_{y}}\right)\right] / \\
& \left\{\frac{2 C_{2} b_{2}^{2}+K_{\Phi r}}{G_{2} h_{2}}-\left[\frac{2 C_{2} b_{2}^{2}+K_{\Phi r}}{2 C_{1} b_{1}^{2}}\left(1+\frac{G_{1} h_{1}}{G_{2} h_{2}}\right)\right]-\left[\left(1-\frac{h_{3}}{h_{2}}\right)\left(1-\frac{G_{1} h_{1}+G_{2} h_{3}}{2 C_{1} b_{1}^{2}}\right)\right]\right\}
\end{aligned}
$$


Table1

\begin{tabular}{cccc}
\hline Parameter & Value & Parameter & Value \\
\hline $\mathrm{G}_{1}$ & $16366 \mathrm{~N}$ & $\mathrm{~K}_{\Phi \mathrm{r}}$ & $\begin{array}{c}\text { Adjustable } \\
\text { parameter } \\
\end{array}$ \\
$\mathrm{G}_{2}$ & $148973 \mathrm{~N}$ & $\mathrm{~h}_{1}$ & $0.057 \mathrm{~m}$ \\
$\mathrm{C}_{1}$ & 2.42 & $\mathrm{~h}_{2}$ & $1.401 \mathrm{~m}$ \\
& $\mathrm{MN} / \mathrm{m}$ & & \\
$\mathrm{C}_{2}$ & $0.6 \mathrm{MN} / \mathrm{m}$ & $\mathrm{h}_{3}$ & $0.215 \mathrm{~m}$ \\
$\mathrm{C}_{\mathrm{y}}$ & $0.2 \mathrm{MN} / \mathrm{m}$ & $\mathrm{h}$ & $1.7265 \mathrm{~m}$ \\
$\mathrm{~b}_{1}$ & $0.51 \mathrm{~m}$ & $\mathrm{~h}_{\mathrm{s}}$ & $0.550 \mathrm{~m}$ \\
$\mathrm{~b}_{2}$ & $0.555 \mathrm{~m}$ & & \\
\hline
\end{tabular}

Definition:

$\mathrm{G}_{1}$ The gravity of Bogie's portion above the springs

$\mathrm{G}_{2}$ The gravity of the vehicle body above the springs

$\mathrm{C}_{1}$ One side of the vehicle's vertical stiffness of primary suspension

$\mathrm{C}_{2}$ One side of the vehicle's vertical stiffness of the secondary suspension

$\mathrm{C}_{\mathrm{y}}$ Transverse stiffness of the secondary suspension of the vehicle (whole vehicle)

$\mathrm{K}_{\Phi r}$ Additional anti-roll torsion bar stiffness (whole vehicle)

$h \quad$ The height of the body's center of gravity away from the track surface

$h_{1}$ The height of the gravity of Bogie's portion above the springs from the axle centerline

$h_{2}$ The height of the gravity of the vehicle body above the springs from the axle centerline

$\mathrm{h}_{3}$ The height of the supporting surface of secondary suspension from the axle centerline

$h_{s}$ The height of the air springs' supporting surface away from the track surface

$\mathrm{b}_{1}$ The half distance of the primary suspension's centerline

$\mathrm{b}_{2}$ The half distance of the secondary suspension's centerline

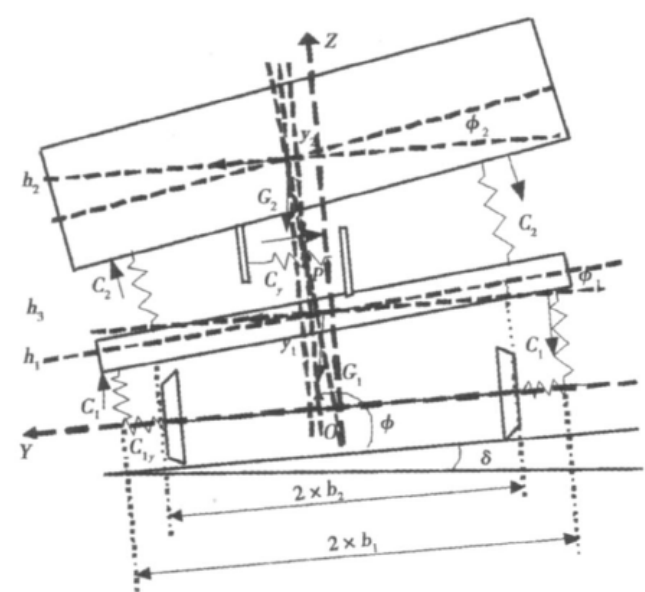

Fig. 1 All the relative parameters sketch

Coefficient is calculated by using the equation. When $\mathrm{K}_{\Phi \mathrm{r}}$ is $0, \mathrm{~S}$ is $1.9576>0.4$.

When additional anti-roll torsion bar stiffness is $3.9 \mathrm{MN}^{*} \mathrm{~m} / \mathrm{rad}$, the condition of the flexible computing coefficient $\mathrm{S}$ is $0.3719<0.4$. 


\section{The design and calculation of anti-roll bar}

\subsection{The calculation of anti-roll bar}

Torsion rigidity including torsional stiffness and the stiffness of torsion bar itself, due to the installation side of the rear anti-roll torsion bar body (or Bolster) the increased roll stiffness (the side of the torsion bar of the roll stiffness) [4].Firstly we calculate the torsional stiffness of the torsion bar, and then calculates the side of the torsion bar roll stiffness [5]. It can refer the anti-roll bar in Malysia Metro:

Side roll torsion bar stiffness can be calculated as following:

When the torsion bar of constant section round bar diameter is $\mathrm{d}$ :

Definition:

$b_{r} \quad$ The nominal length of the torsion bar $\quad k_{r} \quad$ Torsional rigidity of the torsion bar

l The length of the torsion arm G Modulus of rigidity

After calculation, when $\mathrm{d}=57 \mathrm{~mm}$, br $=1520 \mathrm{~mm}, \mathrm{l}=255 \mathrm{~mm} . \mathrm{K}=1.95 \mathrm{MN} * \mathrm{M} / \mathrm{rad}$

\subsection{Build the model in CATIA V5}

Using the part design module, build the torsion bar, torsion arm, joint sets, joint bearing model. Then use the assembly design module, assemble the above-mentioned parts and define its material 50CrVA steel.

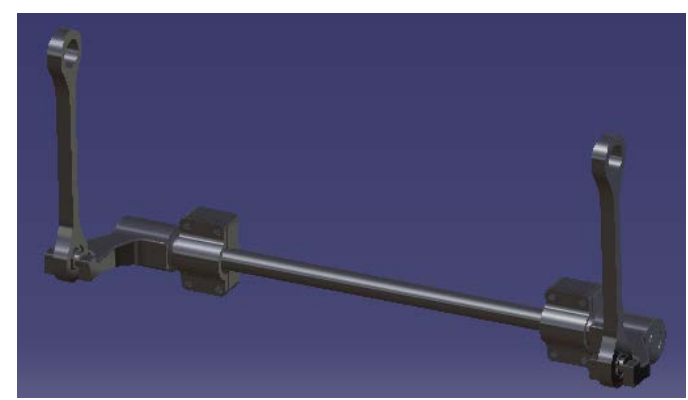

Fig. 2 The model of Anti-roll bar

\section{Analysis on intensity}

\subsection{The calculation of surface force density}

Under normal operating loads, according to the "high-speed trains and dynamic strength test bus specification (Provisional)" provides that: the centrifugal force before unbalanced load $\mathrm{F}_{1}$ is as following:

$$
\mathrm{F}_{1}=0.1 \mathrm{G}_{2}=0.1 \times 148973=14897.3 \mathrm{~N}
$$

Bogie side of the spring vertical stiffness:

$\mathrm{K}_{\mathrm{z}}=0.6 \mathrm{MN} / \mathrm{m}$, a width of $2 * \mathrm{~b}_{2}=1.11 \mathrm{~m}$,

The bogie roll stiffness of the secondary suspension:

Maximum torque of the roll torsion of the bar's side is:

The maximum vertical force acting on the torsion arm end is:

$\mathrm{F}_{\mathrm{d}}=\mathrm{M}_{\mathrm{d}} / \mathrm{b}_{\mathrm{r}}=7366 / 1.52=4846 \mathrm{~N}$

The surface force density is:

$\sigma=\mathrm{F}_{\mathrm{d}} / \mathrm{A}=4846 / 1926 * 10^{6}=2.517 * 10^{6} \mathrm{Mpa}$ 


\subsection{Analysis in CATIA V5}

During analysis on intensity, it needs to simplify the model [6]. Using the Generative Structural Analysis model, the load is applied at one end, at the other end of the torsion bar clamp arm surface, constrain the bearing by surface glider bound. Grid size is $5 \mathrm{~mm}$.



Fig. 3 Constraints and load on the model

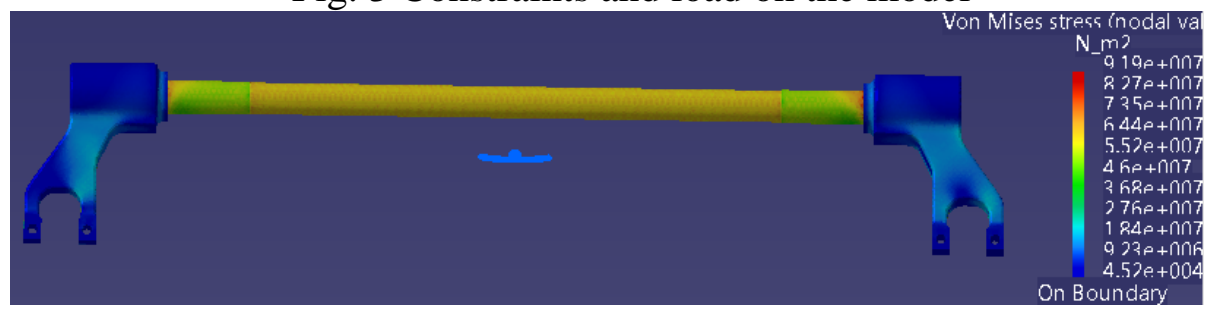

Fig. 4 Result of Von Mises stress

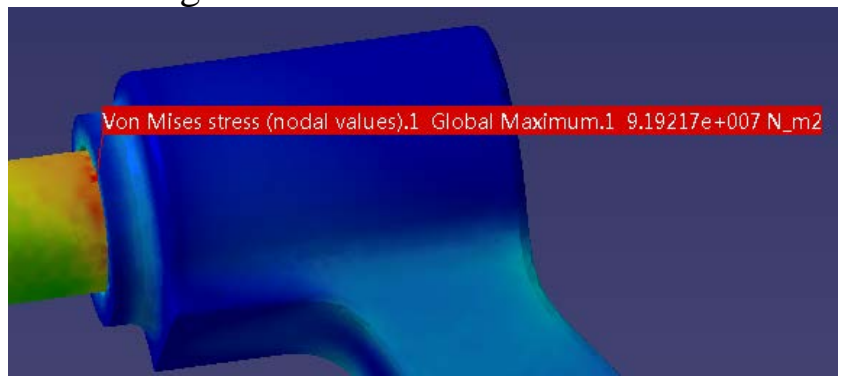

Fig.5 The position of the maximum Von Mises stress

50CrVA steel's fatigue limit is 648.27Mpa. The maximum Von Mises stress is 92Mpa and the safety factor is 7 , which meet the requirement.

\section{Summary}

It is proved that this method is completely feasible in the computer environment. It is better for us to manufacture the product and test it in practical.

\section{References}

[1] Lihui Ren, Zhenggang Lu, Study Articulated High Speed Passenger antiroll stabilizer parameters, J. Railway locomotive \& Car. (2002.01) 11-13.

[2] Jiandong Jiang, Haifu Mao, Pei Li, Analysis of Anti-roll Torsion Bar of Passenger Bogie, J. Railway locomotive \& Car. (2004.10) 4-7.

[3] Xueliang Li, Gang Shen, The research on flexibility coefficient, J. Rolling Stock. (2011.08) 4-6.

[4] Zhongjie Wang, Research and Manufacture of Anti-rolling Bar Equipment for Guangzhou Merto Line 3, J. Urban Mass Transit. (2008) 40-42.

[5] Xianjian Yin, Peng Zhang, The design of Anti-roll bar in rail vehicles, J. Electric Locomotives \& Mass Transit Vehicles. (2005.05) 21-22 
[6] Huadong Duan, Analysis on intensity and stiffness of anti-rolling bar for the bogie of mass transit vehicles, J. Electric Locomotives \& Mass Transit Vehicles. (2010.03) 41-44 